\title{
Front Matter: Volume 9036
}

, "Front Matter: Volume 9036," Proc. SPIE 9036, Medical Imaging 2014:

Image-Guided Procedures, Robotic Interventions, and Modeling, 903601 (25 April 2014); doi: 10.1117/12.2064312

SPIE. Event: SPIE Medical Imaging, 2014, San Diego, California, United States 


\title{
PROGRESS IN BIOMEDICAL OPTICS AND IMAGING

\section{Medical Imaging 2014}

\section{Image-Guided Procedures, Robotic Interventions, and Modeling}

\author{
Ziv R. Yaniv \\ David R. Holmes III \\ Editors
}

\author{
18-20 February 2014 \\ San Diego, California, United States
}

Sponsored by

SPIE

Cosponsored by

Modus Medical Devices Inc. (Canada) • XIFIN, Inc. • Ventana Medical Systems Inc. • Intrace Medical (Switzerland) • Siemens

Cooperating Organizations

AAPM-American Association of Physicists in Medicine (United States) - APS—American Physiological Society • CARS—Computer Assisted Radiology and Surgery (Germany) • The DICOM Standards Committee • Medical Image Perception Society (United States) • Radiological Society of North America (United States) - Society for Imaging Informatics in Medicine (United States) • World Molecular Imaging Society

Published by

SPIE 
The papers included in this volume were part of the technical conference cited on the cover and title page. Papers were selected and subject to review by the editors and conference program committee. Some conference presentations may not be available for publication. The papers published in these proceedings reflect the work and thoughts of the authors and are published herein as submitted. The publisher is not responsible for the validity of the information or for any outcomes resulting from reliance thereon.

Please use the following format to cite material from this book:

Author(s), "Title of Paper," in Medical Imaging 2014: Image-Guided Procedures, Robotic Interventions, and Modeling, edited by Ziv R. Yaniv, David R. Holmes III, Proceedings of SPIE Vol. 9036 (SPIE, Bellingham, WA, 2014) Article CID Number.

ISSN: 1605-7422

ISBN: 9780819498298

Published by

SPIE

P.O. Box 10, Bellingham, Washington 98227-0010 USA

Telephone +1 3606763290 (Pacific Time) · Fax +1 3606471445

SPIE.org

Copyright (@ 2014, Society of Photo-Optical Instrumentation Engineers.

Copying of material in this book for internal or personal use, or for the internal or personal use of specific clients, beyond the fair use provisions granted by the U.S. Copyright Law is authorized by SPIE subject to payment of copying fees. The Transactional Reporting Service base fee for this volume is $\$ 18.00$ per article (or portion thereof), which should be paid directly to the Copyright Clearance Center (CCC), 222 Rosewood Drive, Danvers, MA 01923. Payment may also be made electronically through CCC Online at copyright.com. Other copying for republication, resale, advertising or promotion, or any form of systematic or multiple reproduction of any material in this book is prohibited except with permission in writing from the publisher. The CCC fee code is $1605-7422 / 14 / \$ 18.00$.

Printed in the United States of America.

Publication of record for individual papers is online in the SPIE Digital Library.

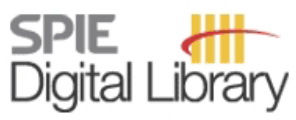

SPIEDigitallibrary.org

Paper Numbering: Proceedings of SPIE follow an e-First publication model, with papers published first online and then in print and on CD-ROM. Papers are published as they are submitted and meet publication criteria. A unique, consistent, permanent citation identifier (CID) number is assigned to each article at the time of the first publication. Utilization of CIDs allows articles to be fully citable as soon as they are published online, and connects the same identifier to all online, print, and electronic versions of the publication. SPIE uses a six-digit CID article numbering system in which:

- The first four digits correspond to the SPIE volume number.

- The last two digits indicate publication order within the volume using a Base 36 numbering

system employing both numerals and letters. These two-number sets start with 00, 01, 02, 03, 04, $05,06,07,08,09,0 A, 0 B \ldots$. 0Z, followed by 10-1Z, 20-2Z, etc.

The CID Number appears on each page of the manuscript. The complete citation is used on the first page, and an abbreviated version on subsequent pages. Numbers in the index correspond to the last two digits of the six-digit CID Number. 


\title{
Contents
}

\author{
xv Conference Committee \\ xvii Introduction \\ xix 2014 Medical Imaging Paper Award Recipients
}

\section{SESSION 1 ABDOMINAL PROCEDURES}

903602 Innovative approach for in-vivo ablation validation on multimodal images [9036-1] O. Shahin, Univ. of Lübeck (Germany); G. Karagkounis, D. Carnegie, Johns Hopkins School of Medicine (United States); A. Schlaefer, Univ. of Lübeck (Germany); E. Boctor, Johns Hopkins School of Medicine (United States) and Johns Hopkins Univ. (United States)

903603 Model-based formalization of medical knowledge for context-aware assistance in laparoscopic surgery [9036-2]

D. Katić, Karlsruhe Institute of Technology (Germany); A.-L. Wekerle, Univ. of Heidelberg (Germany); F. Gärtner, Karlsruhe Institute of Technology (Germany); H. G. Kenngott, B. P. Müller-Stich, Univ. of Heidelberg (Germany); R. Dillmann, S. Speidel, Karlsruhe Institute of Technology (Germany)

903604 Software-assisted post-interventional assessment of radiofrequency ablation [9036-3] C. Rieder, B. Geisler, Fraunhofer MEVIS (Germany); P. Bruners, P. Isfort, H.-S. Na, RWTH Aachen Univ. Hospital (Germany); A. H. Mahnken, Univ. Hospital Marburg (Germany); H. K. Hahn, Fraunhofer MEVIS (Germany)

903605 Anatomical parameterization for volumetric meshing of the liver [9036-4] S. Vera, Alma IT Systems (Spain) and Univ. Autònoma de Barcelona (Spain); M. A. González Ballester, Alma IT Systems (Spain), ICREA - Institució Catalana de Recerca i Estudis Avançats (Spain), and Univ. Pompeu Fabra (Spain); D. Gil, Univ. Autònoma de Barcelona (Spain)

903606 Preliminary clinical trial in percutaneous nephrolithotomy using a real-time navigation system for percutaneous kidney access [9036-5]

P. L. Rodrigues, A. H. J. Moreira, ICVS/3B's (Portugal) and Univ. of Minho (Portugal); N. F. Rodrigues, ICVS/3B's (Portugal) and Polytechnic Institute of Cávado and Ave (Portugal); A. C. M. Pinho, J. C. Fonseca, Univ. of Minho (Portugal); E. Lima, ICVS/3B's (Portugal); J. L. Vilaça, ICVS/3B's (Portugal) and Polytechnic Institute of Cávado and Ave (Portugal)

\section{SESSION 2 LAPAROSCOPY/ENDOSCOPY/BRONCHOSCOPY/COLONOSCOPY}

903607 Construction of a multimodal CT-video chest model [9036-6]

P. D. Byrnes, W. E. Higgins, The Pennsylvania State Univ. (United States) 
903608 Visual tracking of da Vinci instruments for laparoscopic surgery [9036-7]

S. Speidel, E. Kuhn, S. Bodenstedt, S. Röhl, Karlsruhe Institute of Technology (Germany);

H. Kenngott, B. Müller-Stich, Univ. of Heidelberg (Germany); R. Dillmann, Karlsruhe Institute of Technology (Germany)

903609 Computer-assisted polyp matching between optical colonoscopy and CT colonography: a phantom study [9036-8]

H. R. Roth, T. E. Hampshire, E. Helbren, M. Hu, Univ. College London (United Kingdom);

R. Vega, Univ. College Hospital (United Kingdom); S. Halligan, D. J. Hawkes, Univ. College London (United Kingdom)

9036 OA Adaptive fiducial-free registration using multiple point selection for real-time electromagnetically navigated endoscopy [9036-9]

X. Luo, K. Mori, Nagoya Univ. (Japan)

9036 OB Geometric estimation of intestinal contraction for motion tracking of video capsule endoscope [9036-10]

L. Mi, G. Bao, K. Pahlavan, Worcester Polytechnic Institute (United States)

9036 OC Motion magnification for endoscopic surgery [9036-11]

A. J. McLeod, J. S. H. Baxter, S. de Ribaupierre, T. M. Peters, Robarts Research Institute (Canada)

9036 OD Reconstruction and feature selection for desorption electrospray ionization mass spectroscopy imagery [9036-12]

Y. Gao, The Univ. of Alabama at Birmingham (United States); L. Zhu, Stony Brook Univ. (United States); I. Norton, Brigham And Women's Hospital (United States); N. Y. R. Agar, Brigham and Women's Hospital (United States) and Harvard Medical School (United States); A. Tannenbaum, Stony Brook Univ. (United States)

9036 OE Automatic standard plane adjustment on mobile C-Arm CT images of the calcaneus using atlas-based feature registration [9036-13]

M. Brehler, J. Görres, German Cancer Research Ctr. (DFKZ) (Germany); I. Wolf, Mannheim Univ. of Applied Sciences (Germany); J. Franke, J. von Recum, P. A. Grützner, BG Trauma Ctr. (Germany); H.-P. Meinzer, D. Nabers, German Cancer Research Ctr. (DFKZ) (Germany)

9036 OF Mechanically assisted 3D ultrasound for pre-operative assessment and guiding percutaneous treatment of focal liver tumors [9036-14]

H. Sadeghi Neshat, Robarts Research Institute (Canada) and Univ. of Western Ontario (Canada); J. Bax, CIMTEC (Canada); K. Barker, L. Gardi, J. Chedalavada, Robarts Research Institute (Canada); N. Kakani, Univ. of Western Ontario (Canada); A. Fenster, Robarts Research Institute (Canada), Univ. of Western Ontario (Canada), and CIMTEC (Canada)

9036 OG Optoacoustic sensing for target detection inside cylindrical catheters [9036-15] B. Tavakoli, X. Guo, R. H. Taylor, J. U. Kang, E. M. Boctor, Johns Hopkins Univ. (United States) 
$9036 \mathrm{OH} \quad$ Polarization-sensitive multispectral tissue characterization for optimizing intestinal anastomosis [9036-16]

J. Cha, Johns Hopkins Univ. (United States); B. Triana, Children's National Medical Ctr. (United States) and Princeton Univ. (United States); A. Shademan, A. Krieger, P. C. W. Kim, Children's National Medical Ctr. (United States); J. U. Kang, Johns Hopkins Univ. (United States)

\section{SESSION 4 RESPIRATORY AND CARDIAC MOTION COMPENSATION}

9036 Ol Optical surface scanning for respiratory motion monitoring in radiotherapy: a feasibility study [9036-17]

S. L. Bekke, Herlev Hospital, Univ. of Copenhagen (Denmark) and Technical Univ. of Denmark (Denmark); F. Mahmood, Herlev Hospital, Univ. of Copenhagen (Denmark); J. Helt-Hansen, Technical Univ. of Denmark (Denmark); C. F. Behrens, Herlev Hospital, Univ. of Copenhagen (Denmark)

$90360 \mathrm{~J} \quad$ Statistical analysis of surrogate signals to incorporate respiratory motion variability into radiotherapy treatment planning [9036-18] M. Wilms, J. Ehrhardt, Institute of Medical Informatics, Univ. of Lübeck (Germany); R. Werner, Univ. Medical Ctr. Hamburg-Eppendorf (Germany); M. Marx, H. Handels, Institute of Medical Informatics, Univ. of Lübeck (Germany)

9036 OK Marker-less respiratory motion modeling using the Microsoft Kinect for Windows [9036-19] F. Tahavori, Univ. of Surrey (United Kingdom); M. Alnowami, King Abdulaziz Univ. (Saudi Arabia); K. Wells, Univ. of Surrey (United Kingdom)

$9036 \mathrm{OL}$ Separating complex compound patient motion tracking data using independent component analysis [9036-20]

C. Lindsay, Worcester Polytechnic Institute (United States); K. Johnson, M. A. King, Univ. of Massachusetts Medical School (United States)

\section{SESSION 5 SEGMENTATION}

$90360 \mathrm{M} \quad$ Surgical screw segmentation for mobile C-arm CT devices [9036-21]

J. Görres, M. Brehler, German Cancer Research Ctr. (DFKZ) (Germany); J. Franke, BG Trauma Ctr. (Germany); I. Wolf, Mannheim Univ. of Applied Sciences (Germany); S. Y. Vetter, P. A. Grützner, BG Trauma Ctr. (Germany); H.-P. Meinzer, D. Nabers, German Cancer Research Ctr. (DFKZ) (Germany)

9036 ON A compact method for prostate zonal segmentation on multiparametric MRIs [9036-22] Y. Chi, Singapore Bioimaging Consortium (Singapore); H. Ho, Y. M. Law, Singapore General Hospital (Singapore); Q. Tian, Singapore Bioimaging Consortium (Singapore); H. J. Chen, Biobot Surgical Co. (Singapore); K. J. Tay, Singapore General Hospital (Singapore); J. Liu, Singapore Bioimaging Consortium (Singapore)

903600 Segmentation of risk structures for otologic surgery using the Probabilistic Active Shape Model (PASM) [9036-23]

M. Becker, M. Kirschner, G. Sakas, Technische Univ. Darmstadt (Germany) 
9036 OP Semi-automatic segmentation of vertebral bodies in volumetric MR images using a statistical shape+pose model [9036-24]

A. Suzani, A. Rasoulian, S. Fels, R. N. Rohling, P. Abolmaesumi, The Univ. of British Columbia (Canada)

SESSION 6 REGISTRATION

$90360 Q \quad$ Piecewise-rigid 2D-3D registration for pose estimation of snake-like manipulator using an intraoperative $x$-ray projection [9036-26]

Y. Otake, Johns Hopkins Univ. (United States); R. J. Murphy, M. D. Kutzer, Johns Hopkins Univ. Applied Physics Lab. (United States); R. H. Taylor, Johns Hopkins Univ. (United States); M. Armand, Johns Hopkins Univ. Applied Physics Lab. (United States)

9036 OR Deformable registration for image-guided spine surgery: preserving rigid body vertebral morphology in free-form transformations (First Place Young Scientist Award) [9036-27] S. Reaungamornrat, A. S. Wang, A. Uneri, Y. Otake, Z. Zhao, A. J. Khanna, J. H. Siewerdsen, Johns Hopkins Univ. (United States)

9036 OS Hyperspectral imaging for cancer surgical margin delineation: registration of hyperspectral and histological images [9036-28]

G. Lu, Georgia Institute of Technology (United States) and Emory Univ. (United States); L. Halig, D. Wang, Z. G. Chen, Emory Univ. (United States); B. Fei, Georgia Institute of Technology (United States), Emory Univ. (United States), and Winship Cancer Institute, Emory Univ. (United States)

9036 OT Dynamic tracking of a deformable tissue based on 3D-2D MR-US image registration [9036-29]

B. Marami, McMaster Univ. (Canada), Robarts Research Institute (Canada), and Univ. of Western Ontario (Canada); S. Sirouspour, McMaster Univ. (Canada); A. Fenster, Robarts Research Institute (Canada) and Univ. of Western Ontario (Canada); D. W. Capson, Univ. of Victoria (Canada)

9036 OU Target registration error for rigid shape-based registration with heteroscedastic noise [9036-30]

B. Ma, J. Choi, H. M. Huai, York Univ. (Canada)

9036 OV Registration of liver images to minimally invasive intraoperative surface and subsurface data [9036-31]

Y. Wu, Vanderbilt Univ. (United States); D. C. Rucker, The Univ. of Tennessee Knoxville (United States); R. H. Conley, T. S. Pheiffer, A. L. Simpson, Vanderbilt Univ. (United States): S. K. Geevarghese, Vanderbilt Univ. Medical Ctr. (United States); M. I. Miga, Vanderbilt Univ. (United States)

\section{SESSION 7 KEYNOTE AND BENCH TO BEDSIDE}

9036 OW Engineering therapeutic processes: from research to commodity (Keynote Paper) [9036-32] R. L. Galloway Jr., Vanderbilt Univ. (United States) 
9036 0X Integration of intraoperative stereovision imaging for brain shift visualization during imageguided cranial procedures [9036-33]

T. J. Schaewe, Medtronic, Inc. (United States); X. Fan, S. Ji, Dartmouth College (United States); D. W. Roberts, Dartmouth Medical School, Dartmouth College (United States) and Dartmouth Hitchcock Medical Ctr. (United States); K. D. Paulsen, Dartmouth College (United States), Dartmouth Medical School, Dartmouth College (United States), and Dartmouth Hitchcock Medical Ctr. (United States); D. A. Simon, Medtronic, Inc. (United States)

9036 OY Stereoscopic augmented reality using ultrasound volume rendering for laparoscopic surgery in children [9036-34]

J. Oh, X. Kang, E. Wilson, C. A. Peters, T. D. Kane, R. Shekhar, Children's National Medical Ctr. (United States)

\section{SESSION 8 ROBOTICS AND TRACKING}

$90360 Z$ Localization accuracy of sphere fiducials in computed tomography images [9036-35] J.-P. Kobler, J. Díaz Díaz, Leibniz Univ. Hannover (Germany); J. M. Fitzpatrick, Vanderbilt Univ. (United States); G. J. Lexow, O. Majdani, Hannover Medical School (Germany); T. Ortmaier, Leibniz Univ. Hannover (Germany)

903610 On the accuracy of a video-based drill-guidance solution for orthopedic and trauma surgery: preliminary results [9036-36]

J. Magaraggia, Univ. of Erlangen-Nuremberg (Germany) and Siemens AG (Germany); G. Kleinszig, W. Wei, M. Weiten, R. Graumann, Siemens AG (Germany); E. Angelopoulou, J. Hornegger, Univ. of Erlangen-Nuremberg (Germany) and Erlangen Graduate School in Advanced Optical Technologies (SAOT) (Germany)

903611 In vivo reproducibility of robotic probe placement for an integrated US-CT image-guided radiation therapy system [9036-37]

M. A. Lediju Bell, H. T. Sen, I. Iordachita, P. Kazanzides, J. Wong, Johns Hopkins Univ. (United States)

903612 Workflow assessment of 3T MRI-guided transperineal targeted prostate biopsy using a robotic needle guidance [9036-38]

S.-E. Song, K. Tuncali, J. Tokuda, A. Fedorov, Brigham and Women's Hospital (United States); T. Penzkofer, Brigham and Women's Hospital (United States) and RWTH Aachen Univ. Hospital (Germany); F. Fennessy, C. Tempany, Brigham and Women's Hospital (United States); K. Yoshimitsu, Brigham and Women's Hospital (United States) and Tokyo Women's Medical Univ. (Japan); J. Magill, Physical Sciences Inc. (United States); N. Hata, Brigham and Women's Hospital (United States)

903613 A user-friendly automated port placement planning system for laparoscopic robotic surgery [9036-39]

L. G. Torres, Univ. of North Carolina at Chapel Hill (United States); H. Azimian, Hospital for Sick Children (Canada); A. Enquobahrie, Kitware, Inc. (United States) 
903614 Preliminary testing of a compact bone-attached robot for otologic surgery [9036-40] N. P. Dillon, R. Balachandran, Vanderbilt Univ. (United States); A. Motte dit Falisse, Univ. Catholique de Louvain (Belgium); G. B. Wanna, R. F. Labadie, T. J. Withrow, J. Fitzpatrick, R. J. Webster III, Vanderbilt Univ. (United States)

\section{SESSION $9 \quad$ SIMULATION AND MODELING}

903615 Breast deformation modelling: comparison of methods to obtain a patient specific unloaded configuration [9036-41]

B. Eiben, V. Vavourakis, J. H. Hipwell, Univ. College London (United Kingdom); S. Kabus, C. Lorenz, T. Buelow, Philips Research (Germany); D. J. Hawkes, Univ. College London (United Kingdom)

903616 Intraoperative measurement of indenter-induced brain deformation: a feasibility study [9036-42]

S. Ji, X. Fan, Dartmouth College (United States); D. W. Roberts, Dartmouth Hitchcock Medical Ctr. (United States); K. D. Paulsen, Dartmouth College (United States) and Dartmouth Hitchcock Medical Ctr. (United States)

903617 Virtual estimates of fastening strength for pedicle screw implantation procedures [9036-43] C. A. Linte, Rochester Institute of Technology (United States) and Mayo Clinic (United States); J. J. Camp, K. E. Augustine, P. M. Huddleston, R. A. Robb, D. R. Holmes III, Mayo Clinic (United States)

903618 A cost effective and high fidelity fluoroscopy simulator using the Image-Guided Surgery Toolkit (IGSTK) [9036-44]

R. H. Gong, Stanford Univ. School of Medicine (United States); B. Jenkins, R. W. Sze, Z. Yaniv, Children's National Medical Ctr. (United States)

903619 Cochlear implant simulator for surgical technique analysis [9036-45]

R. L. Turok, Vanderbilt Univ. (United States); R. F. Labadie, G. B. Wanna, Vanderbilt Univ. Medical Ctr. (United States); B. M. Dawant, J. H. Noble, Vanderbilt Univ. (United States)

\section{SESSION $10 \quad$ PELVIC PROCEDURES}

9036 1 A Fast prostate segmentation for brachytherapy based on joint fusion of images and labels [9036-46]

S. Nouranian, M. Ramezani, S. S. Mahdavi, The Univ. of British Columbia (Canada); I. Spadinger, W. J. Morris, BC Cancer Agency (Canada); S. E. Salcudean, P. Abolmaesumi, The Univ. of British Columbia (Canada)

9036 1B Evaluating the utility of 3D TRUS image information in guiding intra-procedure registration for motion compensation [9036-47]

T. De Silva, Robarts Research Institute (Canada) and Univ. of Western Ontario (Canada); D. W. Cool, C. Romagnoli, Univ. of Western Ontario (Canada); A. Fenster, Robarts Research Institute (Canada) and Univ. of Western Ontario (Canada); A. D. Ward, Univ. of Western Ontario (Canada) 
9036 1C Toward 3D-guided prostate biopsy target optimization: an estimation of tumor sampling probabilities [9036-48]

P. R. Martin, Univ. of Western Ontario (Canada); D. W. Cool, Univ. of Western Ontario (Canada) and Robarts Research Institute (Canada); C. Romagnoli, Univ. of Western Ontario (Canada); A. Fenster, Univ. of Western Ontario (Canada) and Robarts Research Institute (Canada); A. D. Ward, Univ. of Western Ontario (Canada)

9036 1D Distinguishing benign confounding treatment changes from residual prostate cancer on MRI following laser ablation (Second Place RFW All Conference Best Student Paper Award) [9036-49]

G. Litjens, H. Huisman, Radboud Univ. Nijmegen Medical Ctr. (Netherlands); R. Elliott, Case Western Reserve Univ. (United States); N. Shih, M. Feldman, Univ. of Pennsylvania (United States); S. Viswanath, Case Western Reserve Univ. (United States); J. Fütterer, J. Bomers, Radboud Univ. Nijmegen Medical Ctr. (Netherlands); A. Madabhushi, Case Western Reserve Univ. (United States)

9036 IE MRI-guided prostate focal laser ablation therapy using a mechatronic needle guidance system [9036-68]

J. Cepek, Robarts Research Institute (Canada) and Univ. Of Western Ontario (Canada);

U. Lindner, S. Ghai, S. R. H. Davidson, J. Trachtenberg, Univ. Health Network (Canada);

A. Fenster, Robarts Research Institute (Canada) and Univ. of Western Ontario (Canada)

9036 IF EM-navigated catheter placement for gynecologic brachytherapy: an accuracy study [9036-51]

A. Mehrtash, A. Damato, G. Pernelle, L. Barber, N. Farhat, A. Viswanathan, R. Cormack, T. Kapur, Brigham and Women's Hospital (United States) and Harvard Medical School

(United States)

\section{SESSION 11 ULTRASOUND IMAGE GUIDANCE: JOINT SESSION WITH CONFERENCES 9036 AND 9040}

9036 IG In vivo validation of a 3D ultrasound system for imaging the lateral ventricles of neonates [9036-52]

J. Kishimoto, A. Fenster, Univ. of Western Ontario (Canada) and Robarts Research Institute (Canada); N. Chen, Schulich School of Medicine and Dentistry, Univ. of Western Ontario (Canada); D. Lee, London Health Sciences Ctr., Univ. of Western Ontario (Canada); S. de Ribaupierre, Univ. of Western Ontario (Canada), Schulich School of Medicine and Dentistry, Univ. of Western Ontario (Canada), and London Health Sciences Ctr., Univ. of Western Ontario (Canada)

9036 1H Visualizing positional uncertainty in freehand 3D ultrasound [9036-53] H.-E. Gueziri, M. J. McGuffin, C. Laporte, École de Technologie Supérieure (Canada)

903611 Synthetic aperture imaging in ultrasound calibration [9036-54] G. Ameri, J. S. H. Baxter, A. J. McLeod, U. Jayaranthe, E. C. S. Chen, T. M. Peters, Robarts Research Institute (Canada) and Univ. of Western Ontario (Canada) 
9036 i Efficient feature-based 2D/3D registration of transesophageal echocardiography to x-ray fluoroscopy for cardiac interventions [9036-72]

C. R. Hatt, M. A. Speidel, A. N. Raval, Univ. of Wisconsin-Madison (United States)

$90361 \mathrm{~K}$ Toward standardized mapping for left atrial analysis and cardiac ablation guidance [9036-56]

M. E. Rettmann, D. R. Holmes III, Mayo Clinic (United States); C. A. Linte, Rochester Institute of Technology (United States); D. L. Packer, R. A. Robb, Mayo Clinic (United States)

$90361 \mathrm{~L}$ Intraoperative measurements on the mitral apparatus using optical tracking: a feasibility study [9036-57]

S. Engelhardt, German Cancer Research Ctr. (DKFZ) (Germany); R. De Simone, Univ. of Heidelberg (Germany); D. Wald, German Cancer Research Ctr. (DKFZ) (Germany); N. Zimmermann, S. Al Maisary, C. J. Beller, M. Karck, Univ. of Heidelberg (Germany); H.-P. Meinzer, German Cancer Research Ctr. (DKFZ) (Germany); I. Wolf, German Cancer Research Ctr. (DKFZ) (Germany) and Mannheim Univ. of Applied Sciences (Germany)

$90361 \mathrm{M} \quad$ Ultrasound based mitral valve annulus tracking for off-pump beating heart mitral valve repair [9036-58]

F. P. Li, M. Rajchl, Univ. of Western Ontario (Canada) and Robarts Research Institute (Canada); J. Moore, Robarts Research Institute (Canada); T. M. Peters, Univ. of Western Ontario (Canada), Robarts Research Institute (Canada), and Lawson Health Research Institute (Canada)

9036 1N Patient-specific left atrial wall-thickness measurement and visualization for radiofrequency ablation [9036-59]

J. Inove, Robarts Research Institute (Canada); A. C. Skanes, Univ. of Western Ontario (Canada); J. A. White, Robarts Research Institute (Canada) and Univ. of Western Ontario (Canada); M. Rajchl, M. Drangova, Robarts Research Institute (Canada)

903610 Mapping cardiac fiber orientations from high-resolution DTI to high-frequency 3D ultrasound [9036-60]

X. Qin, Emory Univ. (United States); S. Wang, Yerkes National Primate Research Ctr., Emory Univ. (United States); M. Shen, Emory Univ. (United States); X. Zhang, Yerkes National Primate Research Ctr., Emory Univ. (United States); M. B. Wagner, Emory Univ. (United States); B. Fei, Emory Univ. (United States) and Georgia Insitute of Technology (United States)

\section{POSTER SESSION}

9036 IP Automatic thoracic anatomy segmentation on CT images using hierarchical fuzzy models and registration [9036-25]

K. Sun, Nanchang Hangkong Univ. (China) and Univ. of Pennsylvania (United States);

J. K. Udupa, D. Odhner, Y. Tong, D. A. Torigian, Univ. of Pennsylvania (United States) 
$90361 Q \quad$ Towards enabling ultrasound guidance in cervical cancer high-dose-rate brachytherapy [9036-50]

A. Wong, S. Sojoudia, The Univ. of British Columbia (Canada); M. Gaudet, Ctr. de santé et de services sociaux de Gatineau (Canada); W. W. Yap, BC Cancer Agency (Canada); S. D. Chang, P. Abolmaesumi, The Univ. of British Columbia (Canada); C. Aquino-Parsons, BC Cancer Agency (Canada); M. Moradi, The Univ. of British Columbia (Canada)

$90361 \mathrm{R}$ Detection of tooth fractures in CBCT images using attention index estimation [9036-61] A. Souza, Carestream Health, Inc. (United States); A. Falcão, Univ. Estadual de Campinas (Brazil); L. Ray, Carestream Health, Inc. (United States)

9036 1T Updating a preoperative surface model with information from real-time tracked 2D ultrasound using a Poisson surface reconstruction algorithm [9036-63]

D. Sun, M. E. Rettmann, D. R. Holmes III, Mayo Clinic (United States); C. A. Linte, Rochester Institute of Technology (United States); D. Packer, R. A. Robb, Mayo Clinic (United States)

$90361 \mathrm{U}$ Hand-eye calibration using dual quaternions in medical environment [9036-64] D. Briese, Siemens Healthcare (Germany) and Otto-von-Guericke-Univ. Magdeburg (Germany); C. Niebler, Siemens Healthcare (Germany); G. Rose, Otto-von-Guericke-Univ. Magdeburg (Germany)

$90361 \mathrm{~V}$ Distribution of guidance models for cardiac resynchronization therapy in the setting of multi-center clinical trials [9036-65]

M. Rajchl, K. Abhari, Robarts Research Institute (Canada) and Univ. of Western Ontario (Canada); J. Stirrat, Robarts Research Institute (Canada); E. Ukwatta, D. Cantor, F. P. Li, T. M. Peters, Robarts Research Institute (Canada) and Univ. of Western Ontario (Canada); J. A. White, Robarts Research Institute (Canada) and Libin Cardiovascular Institute, Univ. of Calgary (Canada)

$90361 \mathrm{~W} \quad$ Open framework for management and processing of multi-modality and multidimensional imaging data for analysis and modelling muscular function [9036-66]

D. García Juan, Univ. Hospital of Geneva (Switzerland); B. M. A. Delattre, Philips Healthcare (Switzerland); S. Trombella, Univ. Hospital of Geneva (Switzerland); S. Lynch, Hannover Medical School (Germany); M. Becker, H. F. Choi, MIRALab, Univ. of Geneva (Switzerland); O. Ratib, Univ. Hospital of Geneva (Switzerland)

9036 1X Innovation in aortoiliac stenting: an in vitro comparison [9036-67]

E. Groot Jebbink, Rijnstate Hospital (Netherlands) and MIRA, Univ. of Twente (Netherlands); P. C. J. M. Goverde, Vascular Clinic ZNA (Belgium); J. A. van Oostayen, M. M. P. J. Reijnen, Rijnstate Hospital (Netherlands); C. H. Slump, MIRA, Univ. of Twente (Netherlands)

$90361 Y \quad$ Preliminary study of rib articulated model based on dynamic fluoroscopy images [9036-69] P.-F. Villard, LORIA, CNRS, Univ. de Lorraine (France); P. Escamilla, Inria (France) and GE Healthcare France (France); E. Kerrien, LORIA, CNRS, Univ. de Lorraine (France) and Inria (France); S. Gorges, Y. Trousset, GE Healthcare France (France); M.-O. Berger, LORIA, CNRS, Univ. de Lorraine (France) and Inria (France)

$90361 \mathrm{Z}$ Solving for free-hand and real-time 3D ultrasound calibration with anisotropic orthogonal Procrustes analysis [9036-70]

E. C. S. Chen, Robarts Research Institute (Canada) and Univ. of Western Ontario (Canada); A. J. McLeod, U. L. Jayarathne, Univ. of Western Ontario (Canada); T. M. Peters, Robarts Research Institute (Canada) and Univ. of Western Ontario (Canada) 
903620 Motion and deformation compensation for freehand prostate biopsies [9036-71]

S. Khallaghi, S. Nouranian, S. Sojoudi, H. A. Ashab, L. Machan, S. Chang, P. Black, M. Gleave, L. Goldenberg, P. Abolmaesumi, The Univ. of British Columbia (Canada)

903622 SimlTK: model driven engineering for medical imaging [9036-74] M. Trezise, Queen's Univ. (Canada); D. Gobbi, Univ. of Calgary (Canada); J. Cordy, Queen's Univ. (Canada); P. Abolmaesumi, Queen's Univ. (Canada) and The Univ. of British Columbia (Canada); P. Mousavi, Queen's Univ. (Canada)

903623 Automatic labeling and segmentation of vertebrae in CT images [9036-75] A. Rasoulian, R. N. Rohling, P. Abolmaesumi, The Univ. of British Columbia (Canada)

903624 Design and development of an ultrasound calibration phantom and system [9036-76] A. Cheng, M. K. Ackerman, G. S. Chirikjian, E. M. Boctor, Johns Hopkins Univ. (United States)

903625 Computational modeling and analysis for left ventricle motion using CT/Echo image fusion [9036-77]

J.-Y. Kim, N. Kang, H.-E. Lee, J. D. K. Kim, Samsung Advanced Institute of Technology (Korea, Republic of)

903626 Colonoscope navigation system using colonoscope tracking method based on line registration [9036-78]

M. Oda, H. Kondo, Nagoya Univ. (Japan); T. Kitasaka, Aichi Institute of Technology (Japan); K. Furukawa, R. Miyahara, Nagoya Univ. Graduate School of Medicine (Japan); Y. Hirooka, Nagoya Univ. Hospital (Japan); H. Goto, Nagoya Univ. Graduate School of Medicine (Japan); N. Navab, Technische Univ. München (Germany); K. Mori, Nagoya Univ. (Japan)

903627 Intraoperative imaging of cortical perfusion by time-resolved thermography using cold bolus approach [9036-79]

J. Hollmach, C. Schnabel, N. Hoffmann, Technische Univ. Dresden (Germany); Y. Radev, S. Sobottka, M. Kirsch, G. Schackert, Klinik und Poliklinik für Neurochirurgie, Technische Univ. Dresden (Germany); E. Koch, G. Steiner, Technische Univ. Dresden (Germany)

903628 Registration-based filtering: An acceptable tool for noise reduction in left ventricular dynamic rotational angiography images? [9036-80]

J.-Y. Wielandts, S. De Buck, Katholieke Univ. Leuven (Belgium) and Medical Imaging Research Ctr., Katholieke Univ. Leuven \& UZ Leuven (Belgium); J. Ector, D. Nuyens, Katholieke Univ. Leuven (Belgium); F. Maes, Medical Imaging Research Ctr., Katholieke Univ. Leuven \& UZ Leuven (Belgium) and Katholieke Univ. Leuven (Belgium); H. Heidbuchel, Katholieke Univ. Leuven (Belgium)

903629 Dimensional accuracy of 3D printed vertebra [9036-81]

K. Ogden, N. Ordway, D. Diallo, G. Tillapaugh-Fay, SUNY Upstate Medical Univ. (United States); C. Aslan, Syracuse Univ. (United States)

9036 2A A tool for intraoperative visualization of registration results [9036-82]

F. King, A. Lasso, C. Pinter, G. Fichtinger, Queen's Univ. (Canada)

$90362 \mathrm{~B}$ Effects of deformable registration algorithms on the creation of statistical maps for preoperative targeting in deep brain stimulation procedures [9036-83]

Y. Liu, P.-F. D'Haese, B. M. Dawant, Vanderbilt Univ. (United States) 
9036 2C Design of a tracked ultrasound calibration phantom made of LEGO bricks [9036-84] R. Walsh, M. Soehl, A. Rankin, A. Lasso, G. Fichtinger, Queen's Univ. (Canada)

9036 2D SPECT-US image fusion and clinical applications [9036-85]

J. Hummel, M. Kaar, R. Hoffmann, W. Birkfellner, T. Beyer, A. Staudenherz, M. Figl, Medical Univ. of Vienna (Austria)

9036 2E Dual-projection 3D-2D registration for surgical guidance: preclinical evaluation of performance and minimum angular separation [9036-86]

A. Uneri, Y. Otake, A. S. Wang, Johns Hopkins Univ. (United States); G. Kleinszig, S. Vogt,

Siemens Healthcare (Germany); G. L. Gallia, D. Rigamonti, J.-P. Wolinsky, Z. L. Gokaslan, A. J. Khanna, Johns Hopkins Medical Institute (United States); J. H. Siewerdsen, Johns Hopkins Univ. (United States)

$90362 \mathrm{~F}$ Feasibility of a touch-free user interface for ultrasound snapshot-guided nephrostomy [9036-87]

S. Kotwicz Herniczek, A. Lasso, T. Ungi, G. Fichtinger, Lab. for Percutaneous Surgery, Queen's Univ. (Canada)

$90362 \mathrm{G}$ Active shape models with optimised texture features for radiotherapy [9036-88] K. Cheng, D. Montgomery, F. Yang, D. B. McLaren, Edinburgh Cancer Ctr., Western General Hospital (United Kingdom); S. McLaughlin, Heriot-Watt Univ. (United Kingdom); W. H. Nailon, Edinburgh Cancer Ctr., Western General Hospital (United Kingdom)

$90362 \mathrm{H} \quad$ Heuristic estimation of electromagnetically tracked catheter shape for image-guided vascular procedures [9036-89]

F. N. Mefleh, Clemson Univ. (United States); G. H. Baker, D. M. Kwartowitz, Clemson Univ. (United States) and Medical Univ. of South Carolina (United States)

$903621 \quad$ A dimensionless dynamic contrast enhanced MRI parameter for intra-prostatic tumour target volume delineation: initial comparison with histology [9036-90]

W. T. Hrinivich, Univ. of Western Ontario (Canada), Robarts Imaging Research Lab. (Canada), and London Regional Cancer Program (Canada); E. Gibson, Univ. of Western Ontario (Canada) and Robarts Imaging Research Lab. (Canada); M. Gaed, Univ. of Western Ontario (Canada), Robarts Imaging Research Lab. (Canada), and Lawson Health Research Institute (Canada); J. A. Gomez, M. Moussa, Univ. of Western Ontario (Canada); C. A. McKenzie, Univ. of Western Ontario (Canada) and Robarts Imaging Research Lab. (Canada); G. S. Bauman, Univ. of Western Ontario (Canada), London Regional Cancer Program (Canada), and Lawson Health Research Institute (Canada); A. D. Ward, Univ. of Western Ontario (Canada) and London Regional Cancer Program (Canada); A. Fenster, Univ. of Western Ontario (Canada), Robarts Imaging Research Lab. (Canada), and Lawson Health Research Institute (Canada); E. Wong, Univ. of Western Ontario (Canada), London Regional Cancer Program (Canada), and Lawson Health Research Institute (Canada)

9036 2J 3D non-rigid surface-based MR-TRUS registration for image-guided prostate biopsy (Honorable Mention Poster Award) [9036-91]

Y. Sun, Robarts Research Institute (Canada) and Univ. of Western Ontario (Canada); W. Qiu, Robarts Research Institute (Canada); C. Romagnoli, Univ. of Western Ontario (Canada); A. Fenster, Robarts Research Institute (Canada) and Univ. of Western Ontario (Canada) 
9036 2K A new CT prostate segmentation for CT-based HDR brachytherapy (Runner Up Young Scientist Award) [9036-92]

X. Yang, P. Rossi, T. Ogunleye, A. B. Jani, W. J. Curran, T. Liu, Winship Cancer Institute, Emory Univ. (United States)

$90362 \mathrm{~L} \quad$ Identifying MRI markers to evaluate early treatment-related changes post-laser ablation for cancer pain management (Cum Laude Poster Award) [9036-93]

P. Tiwari, Case Western Reserve Univ. (United States); S. Danish, Univ. of Medicine and Dentistry of New Jersey (United States); A. Madabhushi, Case Western Reserve Univ. (United States)

$90362 \mathrm{M}$ Development and evaluation of optical needle depth sensor for percutaneous diagnosis and therapies [9036-94]

K. Palmer, D. Alelyunas, C. McCann, K. Yoshimitsu, T. Kato, S.-E. Song, N. Hata, Brigham and Women's Hospital (United States)

$90362 \mathrm{~N} \quad$ Image to physical space registration of supine breast MRI for image guided breast surgery (Honorable Mention Poster Award) [9036-95]

R. H. Conley, Vanderbilt Univ. (United States); I. M. Meszoely, Vanderbilt Univ. Medical Ctr. (United States); T. S. Pheiffer, J. A. Weis, Vanderbilt Univ. (United States); T. E. Yankeelov,

M. I. Miga, Vanderbilt Univ. (United States) and Vanderbilt Univ. Medical Ctr. (United States)

903620 A global CT to US registration of the lumbar spine [9036-96]

S. Nagpal, Queen's Univ. (Canada); I. Hacihaliloglu, The Univ. of British Columbia (Canada); T. Ungi, Queen's Univ. (Canada); A. Rasoulian, The Univ. of British Columbia (Canada); J. Osborn, St. Paul's Hospital (Canada); V. A. Lessoway, British Columbia Women's Hospital (Canada); R. N. Rohling, The Univ. of British Columbia (Canada); D. P. Borschneck, Kingston General Hospital (Canada); P. Abolmaesumi, The Univ. of British Columbia (Canada); P. Mousavi, Queen's Univ. (Canada)

9036 2P Rigid point registration circuits [9036-97]

J. M. Fitzpatrick, Vanderbilt Univ. (United States)

$90362 Q \quad$ Needle localization using a moving stylet/catheter in ultrasound-guided regional anesthesia: a feasibility study [9036-98]

P. Beigi, R. Rohling, The Univ. of British Columbia (Canada)

$90362 R \quad$ Tracked ultrasound calibration studies with a phantom made of LEGO bricks [9036-99] M. Soehl, R. Walsh, A. Rankin, A. Lasso, G. Fichtinger, Queen's Univ. (Canada)

$903625 \quad$ Mapping surgical fields by moving a laser-scanning multimodal scope attached to a robot arm [9036-100]

Y. Gong, T. D. Soper, V. W. Hou, D. Hu, B. Hannaford, E. J. Seibel, Univ. of Washington (United States)

Author Index 


\section{Conference Committee}

Symposium Chairs

Ehsan Samei, Duke University (United States)

David Manning, Lancaster University (United Kingdom)

Conference Chairs

Ziv R. Yaniv, Children's National Medical Center (United States)

David R. Holmes III, Mayo Clinic (United States)

\section{Conference Program Committee}

Purang Abolmaesumi, The University of British Columbia (Canada) Wolfgang Birkfellner, Medizinische Universität Wien (Austria)

Alexandre X. Falcão, Universidade Estadual de Campinas (Brazil)

Baowei Fei, Emory University (United States)

Gabor Fichtinger, Queen's University (Canada)

George J. Grevera, Saint Joseph's University (United States)

Steven L. Hartmann, Medtronic Navigation (United States)

David R. Haynor, University of Washington (United States)

William E. Higgins, The Pennsylvania State University (United States)

Pierre Jannin, Université de Rennes 1 (France)

David M. Kwartowitz, Clemson University (United States)

Lena Maier-Hein, German Cancer Reserach Center (DKFZ)

(Germany)

Michael I. Miga, Vanderbilt University (United States)

Kensaku Mori, Nagoya University (Japan)

Maryam E. Rettmann, Mayo Clinic (United States)

Frank Saver, Siemens Corporation (United States)

Guy Shechter, Philips Healthcare (United States)

Eric J. Seibel, University of Washington (United States)

Robert J. Webster III, Vanderbilt University (United States)

Jay B. West, Elekta, Inc. (United States)

Ivo Wolf, Mannheim University of Applied Sciences (Germany)

Kenneth H. Wong, Virginia Polytechnic Institute and State University

(United States)

\section{Session Chairs}

1 Abdominal Procedures

Pierre Jannin, Université de Rennes 1 (France)

Ivo Wolf, Mannheim University of Applied Sciences (Germany) 
2 Laparoscopy/Endoscopy/Bronchoscopy/Colonoscopy

William E. Higgins, The Pennsylvania State University (United States)

Kensaku Mori, Nagoya University (Japan)

3 Novel Intraoperative Imaging and Visualization

David R. Haynor, University of Washington (United States)

Eric J. Seibel, University of Washington (United States)

4 Respiratory and Cardiac Motion Compensation

Wolfgang Birkfellner, Medizinische Universität Wien (Austria)

Jay B. West, Elekta, Inc. (United States)

5 Segmentation

Alexandre X. Falcão, Universidade Estadual de Campinas (Brazil)

Purang Abolmaesumi, The University of British Columbia (Canada)

6 Registration

Steven L. Hartmann, Medtronic Navigation (United States)

Lena Maier-Hein, German Cancer Reserach Center (DKFZ)

(Germany)

7 Keynote and Bench to Bedside

David R. Holmes III, Mayo Clinic (United States)

Ziv R. Yaniv, Children's National Medical Center (United States)

8 Robotics and Tracking

David M Kwartowitz, Clemson University (United States)

Robert J. Webster III, Vanderbilt University (United States)

9 Simulation and Modeling

Michael I. Miga, Vanderbilt University (United States)

Kenneth H. Wong, Virginia Polytechnic Institute and State University (United States)

10 Pelvic Procedures

Frank Sauer, Siemens Corporation (United States)

Tamas Ungi, Queen's University (Canada)

11 Ultrasound Image Guidance: Joint Session with Conferences 9036 and 9040

Purang Abolmaesumi, The University of British Columbia (Canada) Johan G. Bosch, Erasmus University Rotterdam (Netherlands)

12 Cardiac Procedures

Baowei Fei, Emory University (United States)

Maryam E. Rettmann, Mayo Clinic (United States) 


\section{Introduction}

Welcome to the 2014 edition of the Image-Guided Procedures, Robotic Interventions, and Modeling conference proceedings. This year we received approximately 130 abstract submissions and accepted 100 as full manuscripts which were presented at the conference during the oral and poster sessions.

The keynote presentation by Prof. Robert Galloway from Vanderbilt University drew a large crowd, with 185 attendees. The title of his talk was "Engineering therapeutic processes: from research to commodity." The primary message was that we should strive to take our research from the laboratory and move it into common practice. While this is not a trivial task, it is the only way to ensure that our research has a positive impact on healthcare. In tune with this message, we also hosted a workshop on Commercialization of Medical Research. The workshop included several presentations describing various pathways towards commercialization; including, licensing, establishing a startup company, and collaborating with big industry. We also continued the tradition of having a joint session with the Ultrasonic Imaging and Tomography conference. This time the session included five presentations, and while it was the next-to-last session of the conference, it was very well attended.

This was also the inaugural year for the "Young Scientist Award," a best paper competition which is open both to students and postdoctoral fellows. The prize is awarded to first authors of high quality papers within the Image-Guided Procedures conference. We would like to thank Siemens for sponsoring this award and Frank Saver for coordinating it. The winner of the young scientist award for 2014 was S. Reaungamornrat from Johns Hopkins University for her paper, "Deformable registration for image-guided spine surgery: preserving rigid body vertebral morphology in free-form transformations." The runner up for the young scientist award was X. Yang from Emory University for his paper, "A new CT prostate segmentation for ultrasound-guided CT-based HDR brachytherapy."

We bid farewell to two of our committee's long standing members: Steve Hartmann (Medtronic Inc.) and Jay West (Elekta Inc). Both have served on the committee for 10 years, during which they greatly contributed to the running of the conference and to growing our community. We also welcome three new committee members: Cristian Linte (Rochester Institute of Technology, USA), Parvin Mousavi (Queens University, Canada) and Andrew Wiles (Northern Digital Inc.). We are grateful to all of our committee members for their help in reviewing abstracts, evaluating student papers, and judging posters. Their commitment enables us to maintain the high scientific standards of our conference.

It would be impossible to run this conference without the outstanding support of the SPIE staff members. Thanks to them we are able to focus on the scientific 
aspects of the conference. Working with the SPIE staff onsite always gives us the impression that we are the only conference they have to deal with, and not one out of nine separate conferences all happening at the same time.

Finally, we would like to thank all the attendees who gave talks, presented posters, and actively participated in the meeting. The success of the conference is in no small part due to you. Next year, the conference will take place in Orlando, Florida. We look forward to seeing you there for another successful conference.

Ziv Yaniv David R. Holmes III 


\section{Awards}

\section{Robert F. Wagner Award}

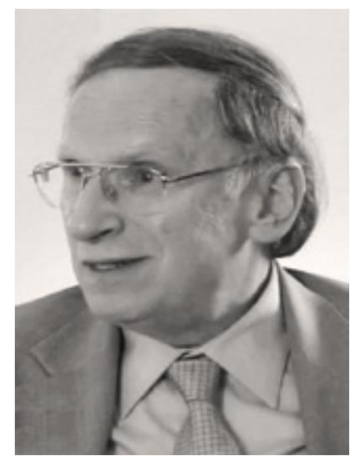

Robert F. Wagner was an active scientist in the SPIE Medical Imaging meeting, starting with the first meeting in 1972 and continuing throughout his career. He ensured that the BRH, and subsequently the $\mathrm{CDRH}$, was a sponsor for the early and subsequent Medical Imaging meetings, helping to launch and ensure the historical success of the meeting. The Robert F. Wagner All-Conference Best Student Paper Award (established 2014 ) is acknowledgment of his many important contributions to the Medical Imaging meeting and his many important advances to the field of medical imaging.

This award is cosponsored by:

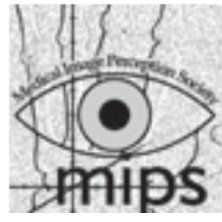

The Medical Image Perception Society

SPIE

2014 Recipients:

First Place: MRI signal and texture features for the prediction of $\mathrm{MCl}$ to Alzheimer's disease progression (9035-78)

A. Martínez-Torteya, J. A. Rodriguez-Rojas, J. M. Celaya-Padilla, J. I. Galván-Tejada, V. M. Treviño-Alvarado, Sr., J. G. Tamez-Peña, Tecnológico de Monterrey (Mexico)

Runner Up: Distinguishing benign confounding treatment changes from residual prostate cancer on MRI following laser ablation (9036-49)

G. Litjens, H. Huisman, Radboud Univ. Nijmegen Medical Ctr. (Netherlands); R. Elliott, Case Western Reserve Univ. (United States); N. Shih, M. Feldman, Univ. of Pennsylvania (United States); S. Viswanath, Case Western Reserve Univ. (United States); J. Fütterer, J. Bomers, Radboud Univ. Nijmegen Medical Ctr. (Netherlands); A. Madabhushi, Case Western Reserve Univ. (United States) 


\section{Conference Awards}

First Place Young Scientist Award

Deformable registration for image-guided spine surgery: preserving rigid body vertebral morphology in free-form transformations (9036-27)

S. Reaungamornrat, A. S. Wang, A. Uneri, Y. Otake, Z. Zhao, A. J. Khanna,

J. H. Siewerdsen, Johns Hopkins Univ. (United States)

Runner Up Young Scientist Award

A new CT prostate segmentation for CT-based HDR brachytherapy (9036-92)

X. Yang, P. Rossi, T. Ogunleye, A. B. Jani, W. J. Curran, T. Liu, Winship Cancer Institute, Emory Univ. (United States)

Cum Laude Poster Award

Identifying MRI markers to evaluate early treatment-related changes post-laser ablation for cancer pain management (9036-93)

P. Tiwari, Case Western Reserve Univ. (United States); S. Danish, Univ. of Medicine and Dentistry of New Jersey (United States); A. Madabhushi, Case Western Reserve Univ.

(United States)

Honorable Mention Poster Award

3D non-rigid surface-based MR-TRUS registration for image-guided prostate biopsy (9036-91)

Y. Sun, Robarts Research Institute (Canada) and Univ. of Western Ontario (Canada);

W. Qiu, Robarts Research Institute (Canada); C. Romagnoli, Univ. of Western Ontario (Canada); A. Fenster, Robarts Research Institute (Canada) and Univ. Of Western Ontario (Canada)

Honorable Mention Poster Award Image to physical space registration of supine breast MRI for image guided breast surgery (9036-95)

R. H. Conley, Vanderbilt Univ. (United States); I. M. Meszoely, Vanderbilt Univ. Medical Ctr. (United States); T. S. Pheiffer, J. A. Weis, Vanderbilt Univ. (United States);

T. E. Yankeelov, M. I. Miga, Vanderbilt Univ. (United States) and Vanderbilt Univ. Medical Ctr. (United States) 